\section{Recovery of Acrylic Acid Using Calcium Peroxide Nanoparticles: Thermodynamics and Continuous Column Study}

\author{
B. S. De, K. L. Wasewar, ${ }^{*}$ V. R. Dhongde, and P. B. Sontakke \\ Advanced Separation and Analytical Laboratory (ASAL), \\ Department of Chemical Engineering, Visvesvaraya National \\ Institute of Technology (VNIT), Nagpur (M.S) 440010, India
}

doi: 10.15255/CABEQ.2016.1055a

Original scientific paper

Received: December 14, 2016 Accepted: February 6, 2018

The thermodynamic parameters $\left(\Delta G^{\circ}, \Delta H^{\circ}\right.$, and $\left.\Delta S^{\circ}\right)$ for adsorption of acrylic acid on $\mathrm{CaO}_{2}$ nanoparticle were estimated in the temperature range of $300.15-313.15 \mathrm{~K}$, which helps to evaluate the feasibility of adsorption process, nature of adsorption process, and affinity of adsorbent toward solute molecule. A dynamic adsorption study in a fixed-bed column was performed using $\mathrm{CaO}_{2}$ nanoparticle for the recovery of acrylic acid from aqueous stream. The breakthrough curves of adsorption system were obtained for different process variables, such as initial acrylic acid concentration (2882-7206 $\left.\mathrm{mg} \mathrm{L}^{-1}\right)$, flow rate $\left(5-9 \mathrm{~mL} \mathrm{~min}^{-1}\right)$, and bed height $(10-20 \mathrm{~cm})$. The bed-depth service time model, Thomas model, Yoon-Nelson model, and deactivation kinetic model were applied to the experimental data to predict the column performance. The data were in good agreement with the deactivation kinetic model. The presented results may be useful for the design of adsorption system using nanoparticles, which can be further extended to other systems.

Keywords:

acrylic acid, calcium peroxide nanoparticles, thermodynamics, continuous column adsorption, modelling

\section{Introduction}

Acrylic acid is widely used for production of flocculants, super-absorbents, adhesives, surface coatings, additives, etc. ${ }^{1}$ The polymers containing acrylic acid and its ester derivatives have unique peculiarities, such as colourless transparency, elasticity, easy adhesion, stability to light, moderate heat and weathering. Acrylic acid expects a global market of KTPA by $2020^{2}$. Acrylic acid can be manufactured by partial oxidation of propene with a yield $50-60 \%$, and the two-step process via acrolein accomplishes an overall yield of $90 \%{ }^{3}$. It is essential to establish an adequate and economic single-step process starting from competitive carbon sources, but petrochemical carbon is not renewable. Therefore, their use adds to global $\mathrm{CO}_{2}$ emissions, and they are expected to become more limited and expensive in future. Alternatively, production of acrylic acid by bio-route seems promising having the drawback of high cost of separation, which is the challenge in its commercialization ${ }^{4}$.

Adsorption is an alternative to other separation processes with specific advantages. In adsorption, the molecules or atoms or ions in gas or liquid, dif-

"Corresponding author: k wasewar@rediffmail.com;

klwasewar@che.vnit.ac.in; dr.kailaswasewar@gmail.com fuse to the surface of a solid and they bond with the solid surface or are detained by uncertain intermolecular forces. Adsorption has been employed successfully for different applications ${ }^{5-21}$. Further, it is a promising separation process for the removal of carboxylic acids ${ }^{22-29}$.

Researchers have a new interest to develop a novel worthwhile adsorbent with high adsorptive capacity. Nanotechnology endeavours new obligations in recent years as they acquire different physical and chemical properties, and may exhibit new characteristics as compared to their bulk form due to their high surface-to-volume ratio, and because of their diminutive size, quantum effects come into play $^{30}$. Also, due to the large surface area per unit mass, nanomaterial may be notably more reactive than larger particles ${ }^{31}$.

Calcium peroxide $\left(\mathrm{CaO}_{2}\right)$ has proven its efficacy in improved remediation of soil ${ }^{32}$. Studies have revealed that the rate of oxidation reaction between calcium peroxide and contaminant is extremely slow ${ }^{33}$. Nanosized $\mathrm{CaO}_{2}$ can be used to overcome this problem, which can enhance the surface-to-volume ratio and the rate of reaction.

The present study focuses on the candidacy of synthesised $\mathrm{CaO}_{2}$ nanoparticles as an effective adsorbent for the recovery of acrylic acid in a contin- 
uous fixed-bed column. The performance of the column was evaluated by various operating parameters, such as inlet acrylic acid concentration, flow rate, and bed height. The bed-depth service time model, Thomas model, Yoon-Nelson model, and deactivation kinetic model were used to predict the dynamic column adsorption. Error analysis was carried out to test the adequacy and accuracy of the model equations. Additionally, the estimation of thermodynamic parameters to fit the measured data to a broader range of temperatures was carried out. This is one of the first studies on continuous adsorption of acrylic acid in a fixed-bed column using $\mathrm{CaO}_{2}$ nanoparticles.

\section{Materials and methods}

\section{Reagents}

The chemicals used were: polyethylene glycol (PEG 200), ammonia solution $\left(\mathrm{NH}_{3} \cdot \mathrm{H}_{2} \mathrm{O}, 25 \%\right.$ ), calcium chloride $\left(\mathrm{CaCl}_{2}, 99.5 \%\right)$, hydrogen peroxide $\left(\mathrm{H}_{2} \mathrm{O}_{2}, 35 \%\right)$, sodium hydroxide $(\mathrm{NaOH})$ (all supplied by Merck India), and Acrylic acid (99\%) (S D Fine-Chem Ltd). Acrylic acid solutions were prepared in double distilled water. All the chemicals were used without further purification or treatment.

\section{Preparation of $\mathrm{CaO}_{2}$ nanoparticles}

A slightly modified co-precipitation technique was used for synthesis of $\mathrm{CaO}_{2}{ }^{34,35}$. In the present case, six grams of $\mathrm{CaCl}_{2}$ was dissolved in $60 \mathrm{~mL}$ distilled water along with $30 \mathrm{~mL}$ ammonia solution $(1 \mathrm{M})$ and $240 \mathrm{~mL}$ PEG 200 in a $1000-\mathrm{mL}$ beaker. PEG 200 is used as a surface modifier, which is important for obtaining nanoparticles as it provides steric stabilisation ${ }^{28}$. The solution was stirred at a constant rate with the continuous addition of $30 \mathrm{~mL}$ $\mathrm{H}_{2} \mathrm{O}_{2}(30 \%)$ at a rate of three drops per minute. A clear and colourless to yellowish solution was obtained after 3 hours of stirring. To precipitate the product, $\mathrm{NaOH}$ solution $(\mathrm{pH} 13)$ was added slowly until $\mathrm{pH} 11.5$ was obtained and the mixture changed to a white suspension. The precipitate was separated by centrifugation at $10000 \mathrm{rpm}$, and the white powder obtained was washed three times with $0.1 \mathrm{M}$ $\mathrm{NaOH}$ solution, followed by washing with distilled water until $\mathrm{pH} 8.4$ for the residue water was achieved. The obtained precipitate was then dried in an evacuated oven for 2 hours at $353.15 \mathrm{~K}$ to obtain $\mathrm{CaO}_{2}$ nanoparticles.

\section{Thermodynamic studies}

Adsorption experiments were conducted to estimate the thermodynamic parameters by varying the temperature $(300.15-313.15 \mathrm{~K})$ at a constant
$\mathrm{CaO}_{2}$ nanoparticle dosage $\left(1 \mathrm{~g} \mathrm{~L}^{-1}\right)$ in the concentration range of $2882-5764 \mathrm{mg} \mathrm{L}^{-1}$. The experiments were carried out by taking $10 \mathrm{~mL}$ of acrylic acid of known concentration in 100-mL Erlenmeyer flask with a known adsorbent dosage. Orbital shaking incubator (REMI S-24BL, India) was employed to shake the mixture for a minimum of 200 minutes, and the samples were centrifuged at $3000 \mathrm{rpm}$ for 5 minutes after shaking to separate the suspended $\mathrm{CaO}_{2}$ nanoparticles. The aqueous concentration of acrylic acid in the supernatant was determined by titration with $\mathrm{NaOH}(0.01 \mathrm{M})$ and phenolphthalein as an indicator. A fresh $\mathrm{NaOH}$ solution was prepared every time for the set of experiments. A few experiments were repeated and analysed, the consistency was observed within $\pm 2 \%$. The $\mathrm{pH}$ was measured by a digital $\mathrm{pH}$ meter (Spectral Lab Instrumental Pvt. Ltd. India), which was calibrated with three buffers ( $\mathrm{pH} 4.0,7.0$ and 10.0) daily.

\section{Column experiments}

The performance of acrylic acid recovery with $\mathrm{CaO}_{2}$ nanoparticles in fixed-bed column was studied through a series of column experiments with various initial concentrations $\left(2882-7206 \mathrm{mg} \mathrm{L}^{-1}\right)$, flow rate $\left(5-9 \mathrm{~mL} \mathrm{~min}^{-1}\right)$, and bed height $(10-20 \mathrm{~cm})$. The details of the experimental conditions are presented in Table 1. The borosilicate glass column (1.2 $\mathrm{cm}$ diameter and $30 \mathrm{~cm}$ length) had four outlets, with three outlets $5 \mathrm{~cm}$ apart, and one $10 \mathrm{~cm}$ from the bottom to collect the effluent at different bed heights. The column was packed with sand and $\mathrm{CaO}_{2}$ nanoparticles to improve the performance. A trial run at the start of the experiment was conducted without nanoparticles. It was observed that sand does not contribute to adsorption and acts as an inert packing. In order to avoid loss of $\mathrm{CaO}_{2}$ nanopar-

Table 1 -Experimental conditions for the adsorption of acrylic acid onto $\mathrm{CaO}_{2}$ nanoparticles in packed column

\begin{tabular}{|c|c|c|c|}
\hline Exp. No. & $\begin{array}{c}\text { Initial } \\
\text { concentration, } C_{0} \\
\left(\mathrm{mg} \mathrm{L}^{-1}\right)\end{array}$ & $\begin{array}{l}\text { Flow rate, } Q \\
\left(\mathrm{~mL} \min ^{-1}\right)\end{array}$ & $\begin{array}{l}\text { Bed height, } Z \\
(\mathrm{~cm})\end{array}$ \\
\hline 1 & 2882 & 5 & 10 \\
\hline 2 & 4323 & 5 & 10 \\
\hline 3 & 5764 & 5 & 10 \\
\hline 4 & 7206 & 5 & 10 \\
\hline 5 & 4323 & 5 & 10 \\
\hline 6 & 4323 & 7 & 10 \\
\hline 7 & 4323 & 9 & 10 \\
\hline 8 & 4323 & 5 & 10 \\
\hline 9 & 4326 & 5 & 15 \\
\hline 10 & 4326 & 5 & 20 \\
\hline
\end{tabular}


ticles, glass wool was placed at the bottom and the top of the column. The flow rate of inlet acrylic acid feed solution of known concentration was regulated using a variable peristaltic pump, and the samples were collected from the column exit at regular intervals, while the concentration of the effluents was analysed by $\mathrm{NaOH}$ titration using phenolphthalein indicator. All the column experiments were carried out at $300.15 \pm 1 \mathrm{~K}$. The operation of the column was stopped when the effluent acrylic acid concentration approximately equalled the influent acrylic acid concentration.

\section{Results and discussion}

\section{Adsorption thermodynamics}

In order to explain the variation in the extent of adsorption with respect to temperature and to fit the measured data to a broader range of temperatures, thermodynamic parameters for acrylic acid adsorption onto $\mathrm{CaO}_{2}$ nanoparticles were quantified at four different temperatures $300.15,305.15,309.15$, and $313.15 \mathrm{~K}$. The thermodynamic study helps evaluate the feasibility of the physicochemical adsorption process. The thermodynamic equilibrium constant or the thermodynamic distribution coefficient, $K_{0}$, can be used to calculate the thermodynamic parameters $\left(\Delta G^{\mathrm{o}}, \Delta H^{\mathrm{o}}\right.$, and $\left.\Delta S^{\mathrm{o}}\right)$, which helps determine the favourable adsorption temperature, nature of the adsorption process (exothermic or endothermic), and the affinity of adsorbent toward the solute molecule $^{36}$. The standard Gibbs free energy change $\Delta G^{\mathrm{o}}$ $\left(\mathrm{kJ} \mathrm{mol}{ }^{-1}\right)$, standard enthalpy change $\Delta H^{\mathrm{o}}\left(\mathrm{kJ} \mathrm{mol}^{-1}\right)$, and standard entropy change $\Delta S^{\mathrm{o}}\left(\mathrm{J} \mathrm{mol}^{-1} \mathrm{~K}^{-1}\right)$ were calculated using the following equations:

$$
\begin{aligned}
\Delta G^{\mathrm{o}} & =-R T \ln K_{0} \\
\ln K_{0} & =\frac{\Delta S^{\mathrm{o}}}{R}-\frac{\Delta H^{\mathrm{o}}}{R T}
\end{aligned}
$$

$K_{0}$ can be defined as:

$$
K_{0}=\frac{a_{\mathrm{s}}}{a_{\mathrm{e}}}=\frac{\gamma_{\mathrm{s}} C_{\mathrm{s}}}{\gamma_{\mathrm{e}} C_{\mathrm{e}}}
$$

where $a_{\mathrm{s}}$ is the activity of the adsorbed acrylic acid, $a_{\mathrm{e}}$ is the activity of acrylic acid at equilibrium, $\gamma_{\mathrm{s}}$ is the activity coefficient of adsorbed acrylic acid, $\gamma_{\mathrm{e}}$ is the activity coefficient of acrylic acid in equilibrium solution, $C_{\mathrm{s}}$ is concentration of acrylic acid adsorbed onto $\mathrm{CaO}_{2}$ nanoparticles $\left(\mathrm{mg} \mathrm{L}^{-1}\right), C_{\mathrm{e}}$ is the acrylic acid concentration in equilibrium solution ( $\left.\mathrm{mg} \mathrm{L}^{-1}\right), R\left(8.3143 \mathrm{~J} \mathrm{~mol}^{-1} \mathrm{~K}^{-1}\right)$ is the universal gas constant, and $T(\mathrm{~K})$ is the absolute temperature.

The values of $K_{0}$ were determined at four different temperatures $(300.15,305.15,309.15$, and

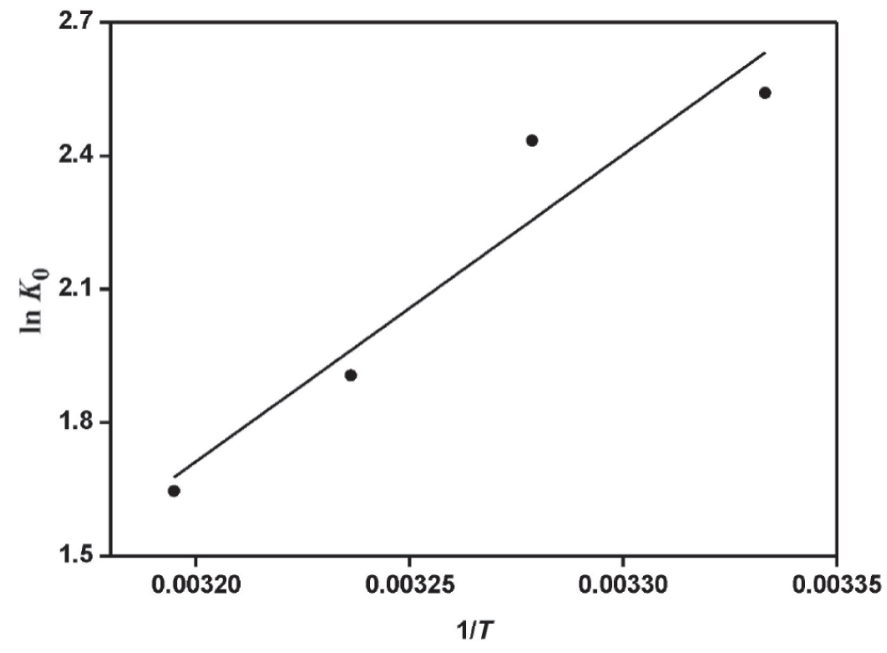

Fig. 1 - Vant Hoff's plot for the adsorption of acrylic acid onto $\mathrm{CaO}_{2}$ nanoparticles for evaluating thermodynamic parameters

$313.15 \mathrm{~K})$ by plotting $\ln \left(C_{\mathrm{s}} / C_{\mathrm{e}}\right)$ versus $C_{\mathrm{s}}$ and extrapolating $C_{\mathrm{s}}$ to zero. The standard Gibbs free energy $\Delta G^{\mathrm{o}}\left(\mathrm{kJ} \mathrm{mol}^{-1}\right)$ was then calculated using equation $1 . K_{0}$ decreased with temperature, indicating an exothermic process. The negative value of $\Delta G^{o}$ signifies the adsorption is favourable and spontaneous, and its increasing value at low temperature indicates that the adsorption process is more favourable at lower temperatures. The values of standard enthalpy change $\Delta H^{\circ}\left(\mathrm{kJ} \mathrm{mol}^{-1}\right)$ and standard entropy change $\Delta S^{\mathrm{o}}\left(\mathrm{J} \mathrm{mol}^{-1} \mathrm{~K}^{-1}\right)$ were obtained from the slope and intercept of Vant Hoff's plot of $\ln K_{0}$ vs $1 / T$ (Fig. 1). All the thermodynamic parameters evaluated are listed in Table 2. The negative value of $\Delta H^{\circ}$ further confirms the exothermic nature of adsorption process, and the negative value of $\Delta S^{0}$ corresponds to a decrease in the degree of freedom of the adsorbed species ${ }^{36}$. This is the normal effect of the chemical adsorption phenomenon where there is a decrease in concentration of the adsorbate in solid-solution interface and its increase onto the solid phase ${ }^{37}$.

\section{Effect of influent concentration}

The initial acrylic acid concentration had a significant effect on column performance. This variable was investigated by varying acrylic acid con-

Table 2 - Thermodynamic parameters for the adsorption of acrylic acid onto $\mathrm{CaO}_{2}$ nanoparticles

\begin{tabular}{c|c|c|c|c}
\hline $\begin{array}{c}\text { Temperature } \\
(\mathrm{K})\end{array}$ & $K_{0}$ & $\begin{array}{c}\Delta G^{\mathrm{o}} \\
\left(\mathrm{kJ} \mathrm{mol}^{-1}\right)\end{array}$ & $\begin{array}{c}\Delta H^{\mathrm{o}} \\
\left(\mathrm{kJ} \mathrm{mol}^{-1}\right)\end{array}$ & $\begin{array}{c}\Delta S^{\mathrm{o}} \\
\left(\mathrm{J} \mathrm{mol}^{-1} \mathrm{~K}^{-1}\right)\end{array}$ \\
\hline 300.15 & 12.69 & -6.33 & & \\
305.15 & 11.40 & -6.17 & & \\
309.15 & 6.72 & -4.89 & -57.367 & -169.340 \\
313.15 & 5.18 & -4.28 & & \\
\hline
\end{tabular}




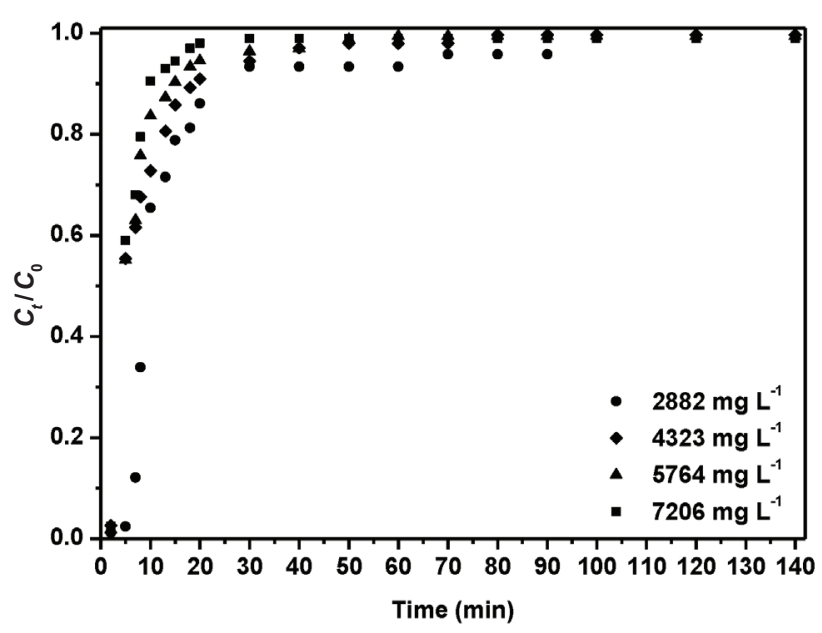

Fig. 2 - Effect of initial acrylic acid concentration on breakthrough curves for adsorption of acrylic acid onto $\mathrm{CaO}$ nanoparticles packed bed column $\left(Z=10 \mathrm{~cm}, Q=5 \mathrm{~mL} \mathrm{~min}^{-1}\right)$

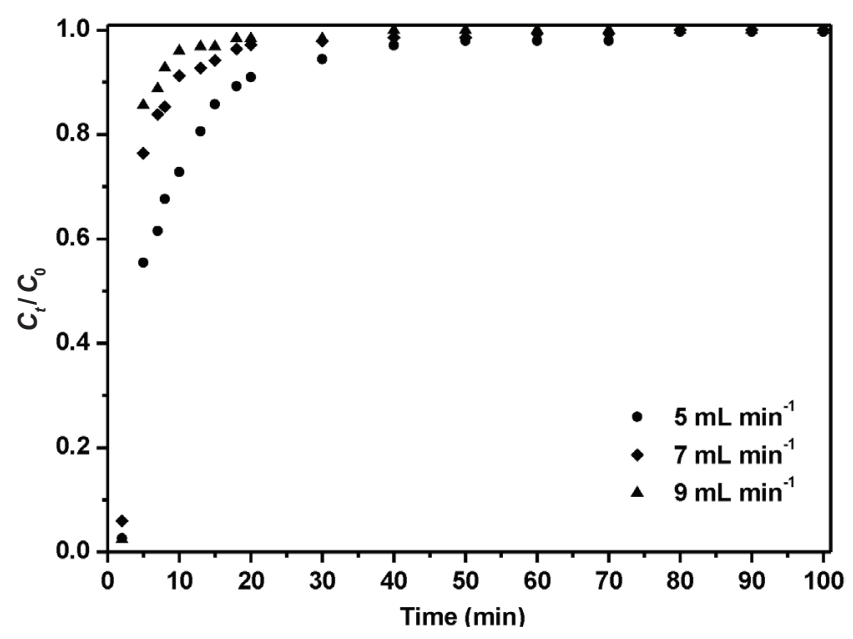

Fig. 3 - Effect of flowrate on breakthrough curves for adsorption of acrylic acid onto $\mathrm{CaO}$, nanoparticles packed bed column $\left(Z=10 \mathrm{~cm}, C_{0}=4323 \mathrm{mg} \mathrm{L}^{-1}\right)$

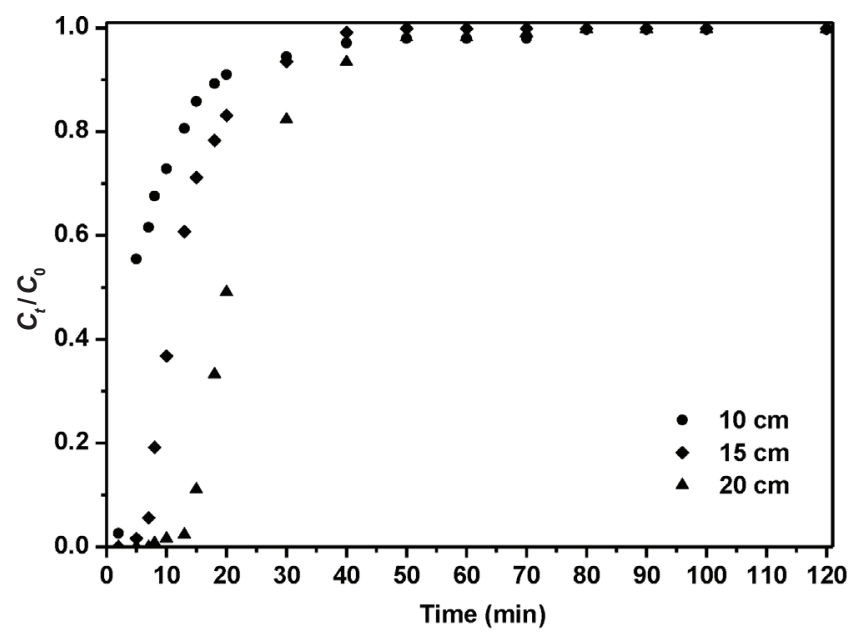

Fig. 4 - Effect of bed height on breakthrough curves for adsorption of acrylic acid onto $\mathrm{CaO}{ }_{2}$ nanoparticles packed bed column $\left(Q=5 \mathrm{~mL} \mathrm{~min}^{-1}, C_{0}=4323 \mathrm{mg} \mathrm{L}^{-1}\right)$ centration from 2882 to $7206 \mathrm{mg} \mathrm{L}^{-1}$. The adsorbent bed height of $10 \mathrm{~cm}$ and a flowrate of $5 \mathrm{~mL} \mathrm{~min}{ }^{-1}$ were used (Fig. 2). With the increasing influent concentration from 2882 to $7206 \mathrm{mg} \mathrm{L}^{-1}$, the breakthrough time decreased from 8.41 to $3.52 \mathrm{~min}$, because of limited adsorption sites, and thus, generated steeper breakthrough curves. In addition, the high acrylic acid concentration provided higher driving force for the mass transfer process, which in turn increased the adsorption capacity, and the rate of mass transfer reduced at lower inlet concentration resulting in slower transport ${ }^{38}$.

\section{Effect of flow rate}

The reduction in column saturation and residence time due to improper utilisation of adsorption bed is a usual phenomenon whenever higher flow rates of the solution are used in the column adsorption process ${ }^{34}$. The breakthrough curves for acrylic acid recovery for different flow rates from 5 to 7 $\mathrm{mL} \mathrm{min}^{-1}$, with initial acrylic acid concentration $4323 \mathrm{mg} \mathrm{L}^{-1}$ and bed height $10 \mathrm{~cm}$ are shown in Fig. 3. It was observed that with higher flow rates, a shorter breakthrough time and higher slope of the curve were obtained, and as the flow rate was increased from 5 to $9 \mathrm{~mL} \mathrm{~min}^{-1}$, the breakthrough time decreased from 2.26 to $1.2 \mathrm{~min}$. This indicates the movement of mass transfer zone with increasing flowrate, which leads to a decrease in the time required to reach the desired breakthrough concentration $^{39}$.

\section{Effect of bed height}

The effect of bed height for the recovery of acrylic acid on column performance with 10, 15, and $20 \mathrm{~cm}$ bed height, at an inlet concentration of

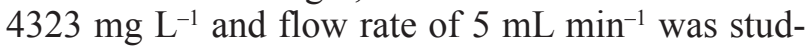
ied (Fig. 4). The results indicated the increase in breakthrough time from 3.67 to $18.89 \mathrm{~min}$ as the bed height was increased from 10 to $15 \mathrm{~cm}$ due to the availability of more sorption sites. The contact time of the influent inside the column increased with increasing bed height, which permitted a deeper diffusion of adsorbate molecules into the adsorbent ${ }^{40}$.

\section{Estimation of parameters for column design}

The different parameters for column design are presented in Table 3. The relationship between beds packed with material in the column and the linear flow rate of solvent with solute is given by empty-bed contact time (EBCT). It is evaluated as:

$$
E B C T=\frac{A_{\mathrm{C}} Z}{Q}
$$

where $A_{\mathrm{C}}\left(\mathrm{m}^{2}\right)$ is the cross-sectional area of the column. 
Table 3 -Adsorption data for acrylic acid adsorption onto $\mathrm{CaO}$, nanoparticles in a fixed bed column at different process conditions

\begin{tabular}{ccccccccc}
\hline $\begin{array}{c}\text { Exp. } \\
\text { no. }\end{array}$ & $\begin{array}{c}\text { EBCT } \\
(\mathrm{min})\end{array}$ & $\begin{array}{c}t_{\mathrm{b}(0.4)} \\
(\mathrm{min})\end{array}$ & $\begin{array}{c}t_{\mathrm{s}(0.95)} \\
(\mathrm{min})\end{array}$ & $\begin{array}{c}q_{\mathrm{b}} \\
\left(\mathrm{mg} \mathrm{g}^{-1}\right)\end{array}$ & $\begin{array}{c}q_{\mathrm{s}} \\
\left(\mathrm{mg} \mathrm{g}^{-1}\right)\end{array}$ & $\begin{array}{c}\mathrm{MTZ} \\
(\mathrm{cm})\end{array}$ \\
\hline 1 & 2.26 & 8.41 & 66.94 & 1212049 & 9647364 & 8.74 \\
2 & 2.26 & 3.67 & 32.24 & 793380 & 6968778 & 8.86 \\
3 & 2.26 & 3.71 & 22.84 & 1069370 & 6582105 & 8.37 \\
4 & 2.26 & 3.52 & 15.71 & 1268256 & 5659124 & 7.75 \\
5 & 2.26 & 3.67 & 32.24 & 793380 & 6968778 & 8.86 \\
6 & 1.61 & 3.48 & 16.28 & 1053138 & 4927837 & 7.86 \\
7 & 1.25 & 3.35 & 9.50 & 1303565 & 3698390 & 6.47 \\
8 & 2.26 & 3.67 & 32.24 & 793380 & 6968778 & 8.86 \\
9 & 3.39 & 10.37 & 32.74 & 1121358 & 3538899 & 10.24 \\
10 & 4.52 & 18.89 & 43.33 & 1361026 & 3122230 & 11.28 \\
\hline
\end{tabular}

The present experimental data reveal that, as the flow rate increased, EBCT decreased (Table 3) and acrylic acid breakthrough occurred more quickly. EBCT increased with the increase in bed height.

The capacity of the bed at breakthrough and saturation point is determined from following equations:

$$
\begin{aligned}
& q_{\mathrm{b}}=\frac{C_{0} Q}{m} \int_{0}^{t_{\mathrm{b}}}\left(1-\frac{C_{t}}{C_{0}}\right) \mathrm{d} t \\
& q_{\mathrm{s}}=\frac{C_{0} Q}{m} \int_{0}^{t_{\mathrm{s}}}\left(1-\frac{C_{t}}{C_{0}}\right) \mathrm{d} t
\end{aligned}
$$

where $q_{\mathrm{b}}$ and $q_{\mathrm{s}}$ are the breakthrough and saturation time capacities ( $\left.\mathrm{mg} \mathrm{g}^{-1}\right)$, respectively, $Q$ is the volumetric flow rate $\left(\mathrm{mL} \mathrm{min}^{-1}\right), m$ is the mass of adsorbent $(\mathrm{g}), t_{\mathrm{b}}$ and $t_{\mathrm{s}}$ are the breakthrough and saturation time (min), respectively.

The length of mass transfer zone (MTZ) can be calculated as the ratio of breakthrough and saturation time capacities:

$$
\mathrm{MTZ}=Z\left(1-\frac{q_{\mathrm{b}}}{q_{\mathrm{s}}}\right)
$$

It can be seen that the increase in bed height leads to a slight increase in MTZ due to the availability of more sorption sites. MTZ decreased with an increase in flow rate due to increased mass transfer rates.

\section{Application of Bed Depth Service Time (BDST) model}

A modified form of Bohart-Adams model, BDST model, is the simplest approach for predicting column design and performance, it expresses

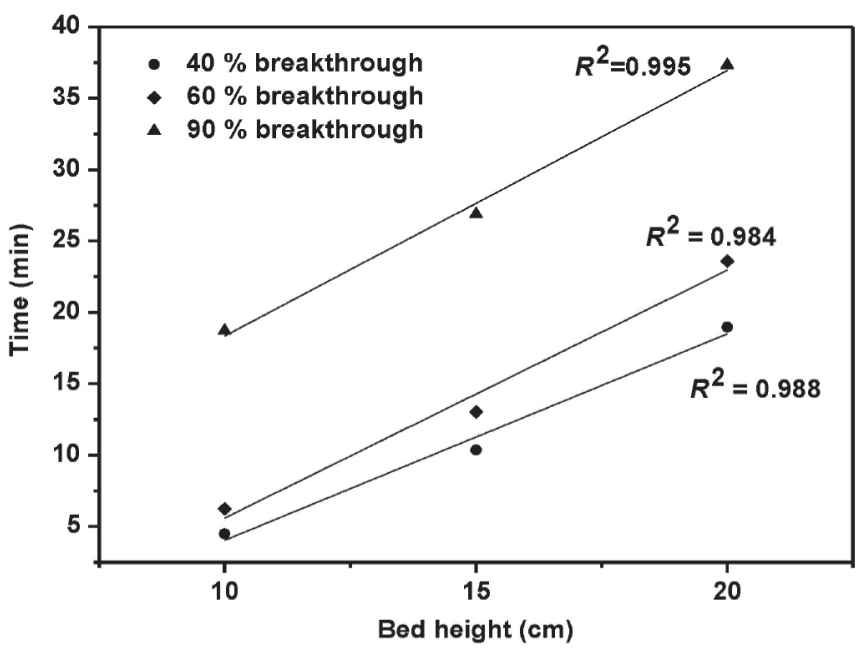

Fig. 5 - Time for breakthrough compared to bed height for acrylic acid adsorption onto $\mathrm{CaO}$, nanoparticles packed bed column (BDST model)

the capacity of the bed at various percentage breakthrough values as a fixed function of operation parameters ${ }^{41}$. It can be represented as follows:

$$
t=\frac{N_{0}}{C_{0} U_{0}} Z-\frac{1}{C_{0} K_{\mathrm{BD}}} \ln \left(\frac{C_{0}}{C_{t}}-1\right)
$$

where $C_{0}, C_{t}, N_{0}, K_{\mathrm{BD}}, U_{0}, Z$, and $t$ are the initial concentration of acrylic acid $\left(\mathrm{mg} \mathrm{mL} \mathrm{mL}^{-1}\right)$, desired concentration of acrylic acid at breakthrough $\left(\mathrm{mg} \mathrm{mL}^{-1}\right)$, adsorption capacity of bed $\left(\mathrm{mg} \mathrm{L}^{-1}\right)$, adsorption rate constant $\left(\mathrm{mL} \mathrm{mg}^{-1} \mathrm{~min}^{-1}\right)$, linear flow velocity of feed to bed $\left(\mathrm{cm} \mathrm{min}{ }^{-1}\right)$, height of column $(\mathrm{cm})$, and service time $(\mathrm{min})$ of the column under the above conditions, respectively. The experimental data obtained from column operation was used to inspect the capability of the BDST model to predict the column performance. The plot of $t$ versus $Z$ for $C_{t} / C_{0}$ values of $0.4,0.6$, and 0.9 , as depicted in Fig. 5, yields a straight line. The values of the adsorption capacity of bed $N_{0}$ and the rate constant $K_{\mathrm{BD}}$, which characterises the rate of solute transfer from the fluid phase to the solid phase ${ }^{42}$, were evaluated from the slope and intercept, respectively. With the steady increase in the slope from 1.44 to $1.86 \mathrm{~min} \mathrm{~cm}^{-1}$ with increasing $C_{t} / C_{0}$, the corresponding values of $N_{0}$ and $K_{\mathrm{BD}}$ can be observed in Table 4. The high $R^{2}$ values (Fig. 5) demonstrated the validity of the BDST model for the adsorption of acrylic acid onto $\mathrm{CaO}_{2}$ nanoparticles.

\section{Application of Thomas model}

The Thomas model is used to predict the maximum solid-phase concentration of the solute on the adsorbent and the adsorption rate constant which plays a significant role in the successful design of column adsorption operation. The mathematical expression of Thomas model is given as follows ${ }^{43}$ : 


$$
\frac{C_{t}}{C_{0}}=\frac{1}{1+\exp \left(\left(k_{\mathrm{Th}} q_{0} m / Q\right)-k_{\mathrm{Th}} C_{0} t\right)}
$$

where $q_{0}$ is the adsorption capacity of the column $\left(\mathrm{mg} \mathrm{g}^{-1}\right), Q$ is the volumetric flow rate $(\mathrm{mL} \mathrm{min})^{-1}$, $m$ is the mass of adsorbent in the column $(\mathrm{g})$, and $k_{\mathrm{Th}}$ is the Thomas rate constant $\left(\mathrm{mL} \mathrm{min}{ }^{-1} \mathrm{mg}^{-1}\right)$. The values of $k_{\mathrm{Th}}$ and $q_{0}$ were determined from a plot of $C_{t} / C_{0}$ vs $t$ using a nonlinear regression method, and the values are present in Table 5. The bestfit isotherm for the column adsorption system was determined by using sum of absolute error (EABS) and sum of square error (SSE) functions. Comparison of predicted and experimental breakthrough curves for different concentrations, flow rates, and bed heights is given in Fig 6. From Table 5, it can be inferred that the Thomas model adsorption capacity of the column $\left(q_{0}\right)$ increases with increase in bed height and decreases with the increase in acrylic acid concentration. The reason for the deviation in experimental results and the predicted Thomas model results might be that this model is based on second-order reaction kinetics, whereas the adsorption is dominated by both interphase mass transfer and chemical reaction kinetics ${ }^{44}$.

Table 4-BDST model parameters for acrylic acid adsorption onto $\mathrm{CaO}_{2}$ nanoparticles in a fixed bed column $\left(\mathrm{C}_{0}=\right.$ $4323.6 \mathrm{mg} \mathrm{L}^{-1}, \stackrel{2}{Q}=5 \mathrm{~mL} \mathrm{~min}^{-1}$ )

\begin{tabular}{c|c|c|c|c}
\hline$C_{t} / C_{0}$ & $\begin{array}{c}a \\
\left(\mathrm{~min} \mathrm{~cm}^{-1}\right)\end{array}$ & $\begin{array}{c}b \\
(\mathrm{~min})\end{array}$ & $\begin{array}{c}K_{\mathrm{bd}} \\
\left(\mathrm{mL} \mathrm{mg}^{-1} \mathrm{~min}^{-1}\right)\end{array}$ & $\begin{array}{c}N_{0} \\
\left(\mathrm{mg} \mathrm{mL}^{-1}\right)\end{array}$ \\
\hline 0.4 & 1.44 & -10.405 & -0.00901 & 13.88 \\
0.6 & 1.73 & -11.745 & 0.00798 & 12.04 \\
0.9 & 1.86 & -0.2646 & 1.92 & 4.29 \\
\hline
\end{tabular}

\section{Application of Yoon and Nelson model}

The Yoon and Nelson model involves fewer column parameters and is applicable for a single component system $^{45}$; it is expressed as:

$$
\frac{C_{t}}{C_{0}-C_{t}}=\exp \left(k_{\mathrm{YN}} t-t_{0.5} k_{\mathrm{YN}}\right)
$$

where $k_{\mathrm{YN}}$ is the Yoon and Nelson rate constant (min), and $t_{0.5}$ is the time required for $50 \%$ adsorbate breakthrough (min). A plot of $C_{t} /\left(C_{0}-C_{t}\right)$ vs. $t$ (Fig. 7) will yield the parameter $k_{\mathrm{YN}}$ and $t_{0.5}$ using a non-linear regressive method. The constants evaluated for different flow rates, bed heights, and concentrations of acrylic acid are listed in Table 5. The rate constant $k_{\mathrm{YN}}$ increased and the $50 \%$ breakthrough time $t_{05}$ decreased with increasing both bed height and acrylic acid concentration (see Table 5). The increase in $C_{0}$ increases driving force for mass transfer, and the higher value of bed height $Z$ offers a longer path for the molecules to travel through the bed, which affects $k_{\mathrm{YN}}$ directly resulting in increased $k_{\mathrm{YN}}$ values.

\section{Application of deactivation kinetic model}

The deactivation kinetic model involving a single activity term denoting a combined effect of active surface area, pore structure, and activity per unit area of solid reactant, was developed primarily for gas-solid adsorption. The model neglects axial dispersion and mass transfer resistance, and assumes isothermal and pseudo-steady-state conditions ${ }^{46,47}$. The deactivation kinetic model is expressed as follows ${ }^{48}$ :

\begin{tabular}{|c|c|c|c|c|c|c|c|c|c|c|c|c|}
\hline \multirow[b]{2}{*}{$\begin{array}{l}\text { Exp. } \\
\text { no. }\end{array}$} & \multicolumn{4}{|c|}{ Thomas model } & \multicolumn{4}{|c|}{ Yoon-Nelson model } & \multicolumn{4}{|c|}{ Deactivation kinetic model } \\
\hline & $\begin{array}{c}K_{\mathrm{T}} \cdot 10^{-5} \\
\left(\mathrm{~L} \mathrm{mg}^{-1} \mathrm{~min}^{-1}\right)\end{array}$ & $\begin{array}{c}q_{0} \\
\left(\mathrm{mg} \mathrm{g}^{-1}\right)\end{array}$ & EABS & SSE & $\begin{array}{c}K_{\mathrm{YN}} \\
(\mathrm{min})\end{array}$ & $\begin{array}{c}t_{0.5} \\
(\mathrm{~min})\end{array}$ & EABS & SSE & $\begin{array}{c}k_{0} \\
\left(\mathrm{~mL} \mathrm{~g}^{-1} \min ^{-1}\right)\end{array}$ & $\begin{array}{c}k_{\mathrm{d}} \\
\left(\min ^{-1}\right)\end{array}$ & EABS & SSE \\
\hline 1 & 2.15 & 2438580 & 2.76 & 0.7243 & 0.0621 & 59.22 & 6.97 & 4.34 & 142.8 & 0.2741 & 0.9681 & 0.09 \\
\hline 2 & 3.08 & 1419981 & 2.12 & 0.4741 & 0.1334 & 28.85 & 5.71 & 3.53 & 85.94 & 0.3039 & 0.8489 & 0.0935 \\
\hline 3 & 2.40 & 1389116 & 2.73 & 0.7759 & 0.1387 & 29.80 & 6.31 & 4.34 & 110 & 0.4102 & 0.6812 & 0.0586 \\
\hline 4 & 5.20 & 2315261 & 3.64 & 1.81 & 0.3749 & 10.45 & 2.24 & 0.95 & 120.2 & 0.4917 & 0.4588 & 0.0342 \\
\hline 5 & 3.08 & 1419981 & 2.12 & 0.4741 & 0.1334 & 28.85 & 5.71 & 3.53 & 85.94 & 0.3039 & 0.8489 & 0.0935 \\
\hline 6 & 6.04 & 1196314 & 1.80 & 0.4495 & 0.2612 & 12.80 & 3.41 & 1.88 & 192.8 & 0.7187 & 0.8315 & 0.4382 \\
\hline 7 & 10.41 & 1767974 & 1.80 & 0.6111 & 0.4504 & 8.817 & 2.28 & 1.22 & 90.88 & 1.053 & 1.14 & 0.2242 \\
\hline 8 & 3.08 & 1419981 & 2.12 & 0.4741 & 0.1334 & 28.85 & 5.71 & 3.53 & 85.94 & 0.3039 & 0.8489 & 0.0935 \\
\hline 9 & 5.89 & 1609526 & 2.37 & 0.9277 & 0.2550 & 13.00 & 0.57 & 0.05 & 72.68 & 0.2556 & 2.85 & 1.15 \\
\hline 10 & 5.57 & 1809459 & 1.76 & 0.7557 & 0.2410 & 15.95 & 1.66 & 0.41 & 63.28 & 0.1967 & 4.20 & 2.74 \\
\hline
\end{tabular}

Table 5 -Packed bed parameters for different models for the adsorption of acrylic acid onto $\mathrm{CaO}_{2}$ nanoparticles 


$$
\frac{C_{t}}{C_{0}}=\exp \left\{\frac{1-\exp \left(\frac{k_{0} m}{Q}\left(1-\exp \left(-k_{\mathrm{d}} t\right)\right)\right)}{1-\exp \left(-k_{\mathrm{d}} t\right)} \exp \left(-k_{\mathrm{d}} t\right)\right\}
$$

where $k_{0}$ and $k_{\mathrm{d}}$ are initial adsorption rate constant $\left(\mathrm{mL} \mathrm{g}^{-1} \mathrm{~min}^{-1}\right)$ and deactivation rate constant $\left(\min ^{-1}\right)$, respectively. It can be noted from Table 5 that $k_{\mathrm{d}}$ increases with the increase in $C_{0}$ and $Q$ a $s$ more molecules are adsorbed on the active sites, but decreases with greater $Z$ owing to the increase in the number of active sites at constant $C_{0}$ and $Q$. In addition, the initial adsorption rate constant, $k_{0}$, is observed to change considerably with $Q$ and $Z$ rather than $C_{0}$, because of the simultaneous change in the weight-time-factor $(\mathrm{m} / \mathrm{Q})$ and effluent concentration. The lower values of error function EABS and SSE, and the breakthrough curves predicted by the deactivation model for different values of flow rate, bed height, and acrylic acid concentration are in better agreement with experimental curves (Fig. 8), and suggest the best fit to the experimental data in comparison with other models.

\section{Conclusions}

The thermodynamic study revealed that adsorption of acrylic acid on $\mathrm{CaO}_{2}$ nanoparticles is feasible and exothermic. The values of standard enthalpy change $\left(\Delta G^{\circ}\right)$ and standard entropy change $\left(\Delta S^{\circ}\right)$ were determined from Vant Hoff's plot to be $-57.36 \mathrm{~kJ} \mathrm{~mol}^{-1}$ and $-169.34 \mathrm{~J} \mathrm{~mol}^{-1} \mathrm{~K}^{-1}$, respectively. The recovery of acrylic acid in continuous fixed-bed column was dependent on initial concentration, flow rate, and bed height. It suggests that lower initial concentration and flow rate, and longer bed height would increase the recovery of acrylic acid from aqueous solution. The flow rate and bed height influence the residence time of influent in the column. However, an increase in bed height increases MTZ inside the column due to greater availability of adsorption sites. The deactivation kinetic model was found to be most suitable for the mathematical account of acrylic acid recovery in a dynamic fixed-bed column. $\mathrm{CaO}_{2}$ nanoparticles can be successfully employed for recovery of acrylic acid from an aqueous stream in an integrated continuous column.

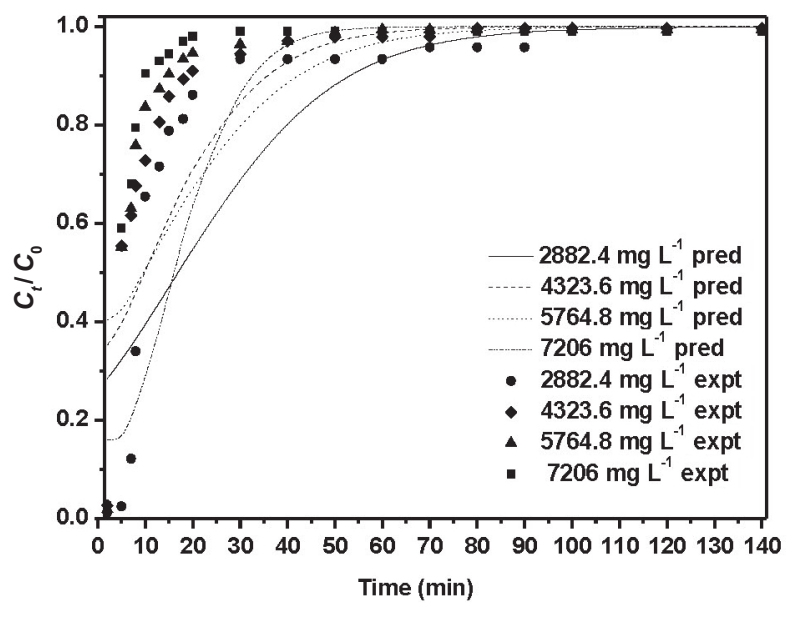

(a)

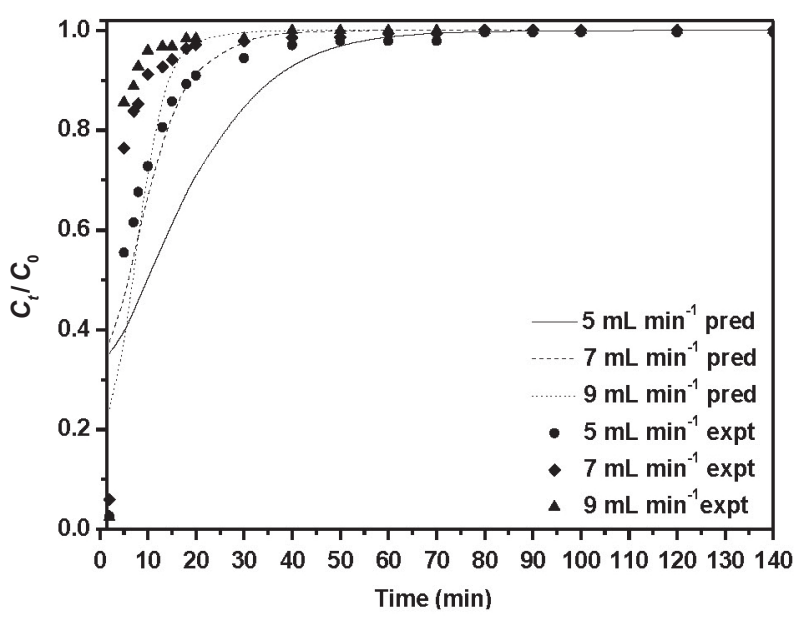

(b)

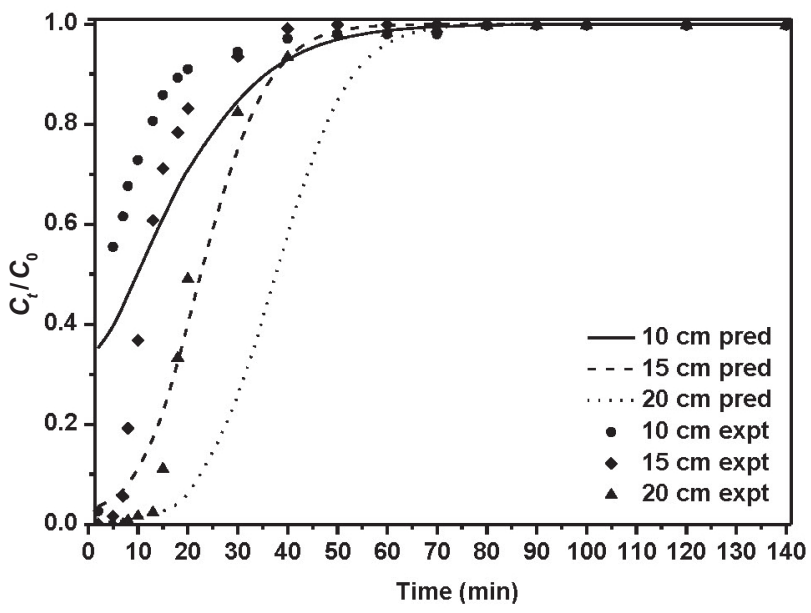

(c)

Fig. 6-Comparison of experimental and predicted breakthrough curves using Thomas model at different (a) influent concentrations, (b) flow rates, and (c) bed heights 


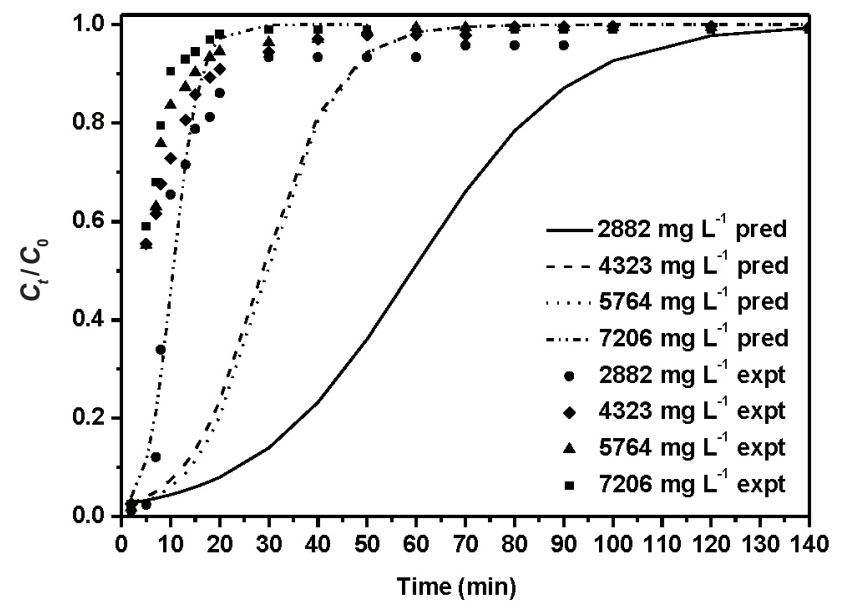

(a)

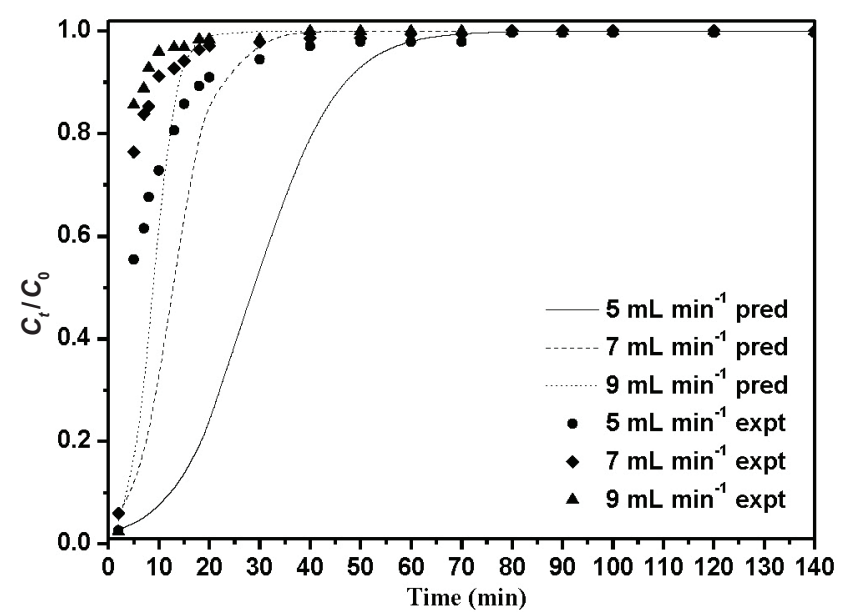

(b)

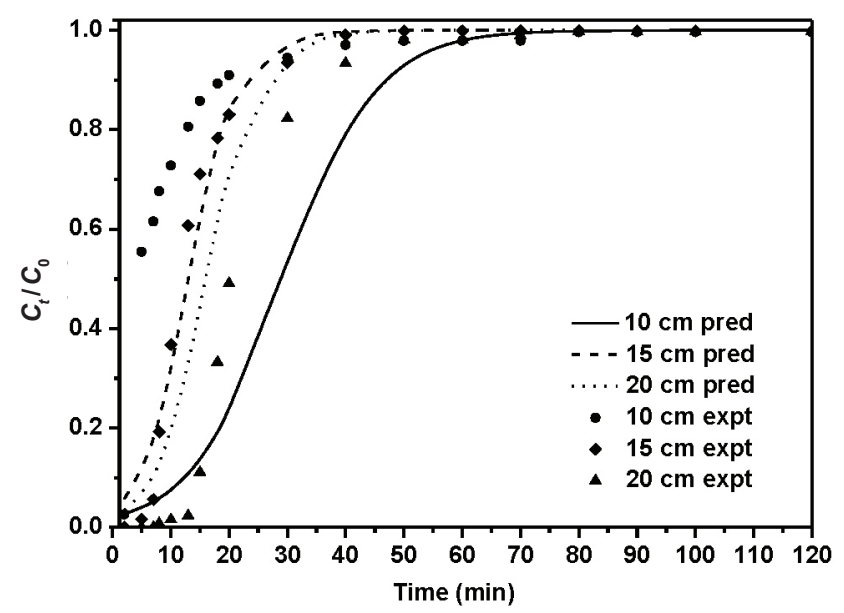

(c)

Fig. 7 - Comparison of experimental and predicted breakthrough curves using Yoon-Nelson model at different (a) influent concentrations, (b) flow rates, and (c) bed heights

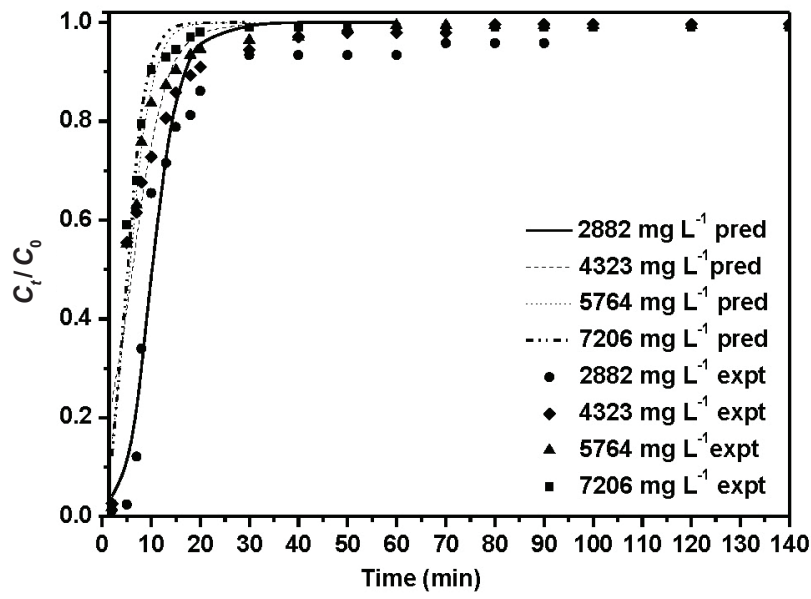

(a)

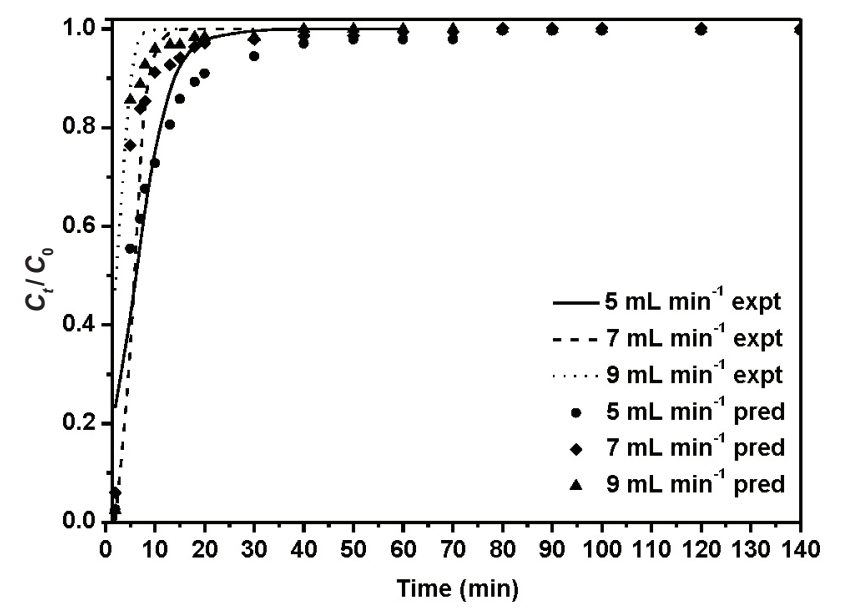

(b)

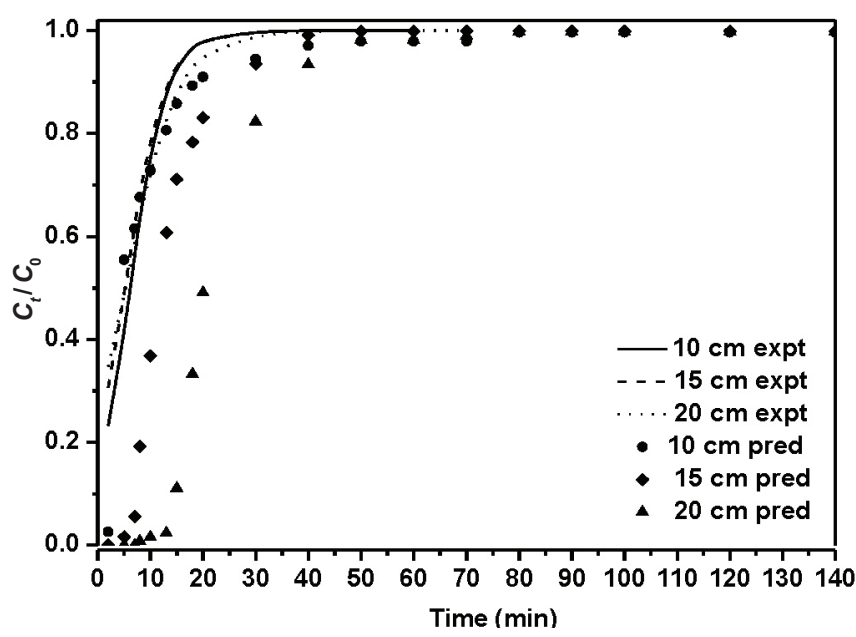

(c)

Fig. 8 - Comparison of experimental and predicted breakthrough curves using deactivation kinetic model at different (a) influent concentrations, (b) flow rates, and (c) bed height 


\section{References}

1. Straathof, A. J. J., Sie, S., Franco, T. T., Van der Wielen, L. A. M., Feasibility of acrylic acid production by fermentation, Appl. Microbiol. Biotechnol. 67 (2005) 727. doi: https://doi.org/10.1007/s00253-005-1942-1

2. Jones, T., Dunwoodie, M., Boucher-Ferte, V., Reiff, O., Chemicals for Beginners: The Vth Edition (2011) 269.

3. Keshav, A., Chand, S., Wasewar, K. L., Reactive extraction of acrylic acid using tri-n-butyl phosphate in different diluents, J. Chem. Eng. Data 54 (2009) 1782. doi: https://doi.org/10.1021/je800856e

4. Bhattacharyya, D., Allison, M. J., Webb, J. R., Zanatta, G. M., Singh, K. S., Grant, S. R., Treatment of an industrial wastewater containing acrylic acid and formaldehyde in an anaerobic membrane bioreactor, J. Hazard. Tox. Rad. Waste 17 (2012) 74.

doi: https://doi.org/10.1061/(ASCE)HZ.2153-5515.0000148

5. Dhongde, V., Wasewar, K. L., De, B. S., Development of nanohybrid adsorbent for defluoridation from aqueous systems, Chemosphere 188 (2017) 354. doi: https://doi.org/10.1016/j.chemosphere.2017.08.153

6. Singh, K., Lataye, D. H., Wasewar, K. L., Removal of fluoride from aqueous solution by using bael (Aegle marmelos) shell activated carbon: Kinetic, equilibrium and thermodynamic study, J. Fluo. Chem. 194 (2017) 23. doi: https://doi.org/10.1016/j.jfluchem.2016.12.009

7. Singh, K., Lataye, D. H., Wasewar, K. L., Removal of fluoride from aqueous solution by using low-cost sugarcane bagasse: Kinetic study and equilibrium isotherm analysis, J. Haz. Tox. Rad. Waste 3 (2016) 1. doi: https://doi.org/10.1061/(ASCE)HZ.2153-5515.0000309

8. Singh, K., Lataye, D. H., Wasewar, K. L., Adsorption of fluoride onto sugarcane bagasse: An application of Taguchi's design of experimental methodology, J. Ind. Wat. Works Ass. 1 (2015) 285.

9. Singh, K., Lataye, D. H., Wasewar, K. L., Yoo, C. K., Removal of fluoride from aqueous solution: status and techniques, Desal. Water Treat. 51 (2013) 3233. doi: https://doi.org/10.1080/19443994.2012.749036

10. Kumar, P., Rao, R., Chand, S., Kumar, S., Wasewar, K. L., Yoo, C. K., Adsorption of lead from aqueous solution onto coir-pith activated carbon, Desal. Water Treat. 51 (2013) 2529.

doi: https://doi.org/10.1080/19443994.2012.749009

11. Kumar, P., Agnihotri, R., Wasewar, K. L., Uslu, H., Yoo, C. $K$., Status of adsorptive removal of dye from textile industry effluent, Desal. Water Treat. 50 (2012) 226. doi: https://doi.org/10.1080/19443994.2012.719472

12. Gulipalli, C. S., Prasad, B., Wasewar, K. L., Batch study, equilibrium, kinetics of adsorption of selenium using rice husk ash (RHA), J. Eng. Sci. Tech. 6 (2011) 590.

13. Kumar, P., Chand, S., Padmini, B. N., Teng, T. T., Wasewar, $K$. $L$., Adsorption of cadmium ions from aqueous solution using granular activated carbon and activated clay, CLEAN: Soil Air Water 38 (2010) 49.

14. Wasewar, K. L., Adsorption of metals onto tea factory waste: a review, Int. J. Res. Rev. App. Sci. 3 (2010) 303.

15. Gulipalli, C. S., Prasad, B., Wasewar, K. L., Removal of selenium by adsorption onto granular activated carbon (GAC) and powdered activated carbon (PAC), CLEAN 37 (2009) 872.

16. Gulipalli, C. S., Prasad, B., Wasewar, K. L., Adsorption of selenium using bagasse fly ash (BFA) CLEAN 37 (2009) 534.
17. Kumar, S., Prasad, B., Wasewar, K. L., Adsorption of tin using granular activated carbon, J. Env. Prot. Sci. 3 (2009) 41.

18. Atif, M., Prasad, B., Wasewar, K. L., Mishra, I. M., Batch Adsorption of $\mathrm{Zn}$ using tea factory waste as an adsorbent, Desalination 244 (2009) 66. doi: https://doi.org/10.1016/j.desal.2008.04.036

19. Atif, M., Prasad, B., Wasewar, K. L., Characterization of factory tea waste as an adsorbent for removal of heavy metals, J. Fut. Eng. Tech. 3 (2008) 47.

20. Rajoriya, R. K., Prasad, B., Mishra, I. M., Wasewar, K. L., Adsorption of benzaldehyde on Granular activated carbon: Kinetics, equilibrium, and thermodynamic, Chem. Biochem. Eng. 22 (2007) 219.

21. Wasewar, K. L., Ravichandra, Y., Kumar, A. M., Godbole, $V$., Adsorption mechanism for the adsorption of heavy metals using tea waste as an adsorbent, J. Future Eng. Tech. 3 (2006) 41 .

22. Inci, I., Removal of citric acid by activated carbon adsorption, Asian J. Chem. 16 (2004) 649.

23. Aşç, Y. S., Hasdemir, I. M., Removal of some carboxylic acids from aqueous solutions by hydrogels, J. Chem. Eng. Data 53 (2008) 2351. doi: https://doi.org/10.1021/je800230t

24. Liu, B. J., Ren, Q. L., Sorption of levulinic acid onto weakly basic anion exchangers: Equilibrium and kinetic studies, J. Coll. and Int. Sci. 294 (2006) 281. doi: https://doi.org/10.1016/j.jcis.2005.07.042

25. Madan, S. S., Wasewar, K. L., Kumar, C. R., Optimization of adsorptive removal of $\alpha$-toluic acid by $\mathrm{CaO}_{2}$ nanoparticles using response surface methodology, Res. Eff. Tech. 3 (2017) 88 .

26. Madan, S. S., Wasewar, K. L., Pandharipande, S. L., Modeling the adsorption of benzeneacetic acid on $\mathrm{CaO}_{2}$ nanoparticles using artificial neural network, Res. Eff. Tech. 2 (2016) 53. doi: https://doi.org/10.1016/j.reffit.2016.10.004

27. Madan, S. S., Wasewar, K. L., Pandharipande, S. L., Artificial Neural Network (ANN) method for modeling of benzeneacetic acid adsorption using $\mathrm{CaO}_{2}$ nanoparticles, Sep. Tech. Chem. Biochem. Petro. Env. Eng. 10 (2016).

28. Waghmare, M. D., Wasewar, K. L., Sonawane, S. S., Kinetics and thermodynamics of picolinic acid adsorption on low cost adsorbent peanut hull, Res. J. Chem. Env. 18 (2014) 87.

29. Madan, S. S., Wasewar, K. L., Kumar, C. R., Adsorption kinetics, thermodynamics, and equilibrium of $\alpha$-toluic acid onto calcium peroxide nanoparticles, Ad. Pow. Tech. 27 (2016) 2112 doi: https://doi.org/10.1016/j.apt.2016.07.024

30. Hochella, M. F., Madden, A. S., Earth's nano-compartment for toxic metals, Elements 1 (2005) 199. doi: https://doi.org/10.2113/gselements.1.4.199

31. Rickerby, D., Morrison, M., Report from the workshop on nanotechnologies for environmental remediation, JRC Ispra. (2007) 16.

32. Park, J. W., Park, B. K., Kim, J. E., Remediation of soil contaminated with 2,4-dichlorophenol by treatment of minced shepherd's purse roots, Arch.Env.Contamin.Tox. 50 (2006) 191. doi: https://doi.org/10.1007/s00244-004-0119-8

33. Northup, A., Cassidy, D., Calcium peroxide $\left(\mathrm{CaO}_{2}\right)$ for use in modified Fenton chemistry, J. Hazard. Mat. 152 (2008) 1164 . doi: https://doi.org/10.1016/j.jhazmat.2007.07.096 
34. Madan, S. S., Upwanshi, W. A, Wasewar, K. L., Adsorption of $\alpha$-toluic acid by calcium peroxide nanoparticles, Desalin. Water Treat. 57 (2016) 16507. doi: https://doi.org/10.1080/19443994.2015.1079255

35. Olyaie, E., Banejad, H., Afkhami, A., Rahmani, A., Khodaveisi, J., Development of a cost-effective technique to remove the arsenic contamination from aqueous solutions by calcium peroxide nanoparticles, Sep. Puri. Tech. 95 (2012) 10 .

36. Boparai, H. K., Joseph, M., O'Carroll, D. M., Kinetics and thermodynamics of cadmium ion removal by adsorption onto nano zerovalent iron particles, J. Hazard. Mat. 186 (2011) 458 . doi: https://doi.org/10.1016/j.jhazmat.2010.11.029

37. Malkoc, E., Nuhoglu, Y., Fixed bed studies for the sorption of chromium (VI) onto tea factory waste, Chem. Eng. Sci. 61 (2006) 436. doi: https://doi.org/10.1016/j.ces.2006.02.005

38. Hussain, S., Aziz, H. A., Isa, M. H., Ahmad, A., Van-Leeuwen, J., Zou, L., Beecham, S., Umar, M., Orthophosphate removal from domestic wastewater using limestone and granular activated carbon, Desalin. 271 (2011) 265. doi: https://doi.org/10.1016/j.desal.2010.12.046

39. Yan, Y., Sun, X., Ma, F., Li, J., Shen, J., Han, W., Liu, X., Wang, $L$., Removal of phosphate from etching wastewater by calcined alkaline residue: Batch and column studies, J. Taiwan Inst. Chem. Eng. 45 (2014) 1709. doi: https://doi.org/10.1016/j.jtice.2013.12.023

40. Roy, A., Chakraborty, S., Kundu, S. P., Adhikari, B., Majumder, $S$. B., Lignocellulosic jute fiber as a bioadsorbent for the removal of azo dye from its aqueous solution: Batch and column studies, J. App. Poly. Sci. 129 (2013) 15. doi: https://doi.org/10.1002/app.38222
41. Goel, J., Kadirvelu, K., Rajagopal, C., Garg, V. K., Removal of lead (II) by adsorption using treated granular activated carbon: batch and column studies, J. Hazard. Mat. 125 (2005) 211. doi: https://doi.org/10.1016/j.jhazmat.2005.05.032

42. Padmesh, T. V., Vijayaraghavan, K., Sekaran, G., Velan, M., Batch and column studies on biosorption of acid dyes on fresh water macro alga Azollafiliculoides, J. Hazard. Mat. 125 (2005) 121 doi: https://doi.org/10.1016/j.jhazmat.2005.05.014

43. Thomas, H. C., Heterogeneous ion exchange in a flowing system, J. Amer. Chem. Soc. 66 (1944) 1664. doi: https://doi.org/10.1021/ja01238a017

44. Aksu, Z., Gönen, F., Biosorption of phenol by immobilized activated sludge in a continuous packed bed: prediction of breakthrough curves, Process Biochem. 39 (2004) 599. doi: https://doi.org/10.1016/S0032-9592(03)00132-8

45. Yoon, Y. H., Nelson, J. H., Application of gas adsorption kinetics: A theoretical model for respirator cartridge service life, The Amer. Ind. Hyg. As. J. 45 (1984) 509. doi: https://doi.org/10.1080/15298668491400197

46. Dahlan, I., Mohamed, A. R., Kamaruddin, A. H., Lee, K. T., Dry $\mathrm{SO}_{2}$ removal process using calcium/siliceous based sorbents: deactivation kinetics based on breakthrough curves, Chem. Eng. Tech. 30 (2007) 663. doi: https://doi.org/10.1002/ceat.200600336

47. Levenspiel, O., Chemical Reaction Engineering, 3rd ed John Wiley \& Sons (Asia), Ltd, New York, 1999, 1-688.

48. Yasyerli, S., Dogu, G., Ar, I., Dogu, T., Activities of copper oxide and $\mathrm{Cu}-\mathrm{V}$ and $\mathrm{Cu}-\mathrm{Mo}$ mixed oxides for $\mathrm{H}_{2} \mathrm{~S}$ removal in the presence and absence of hydrogen and predictions of a deactivation model, Ind. Eng. Chem. Res. 40 (2001) 5206. doi: https://doi.org/10.1021/ie0010621 